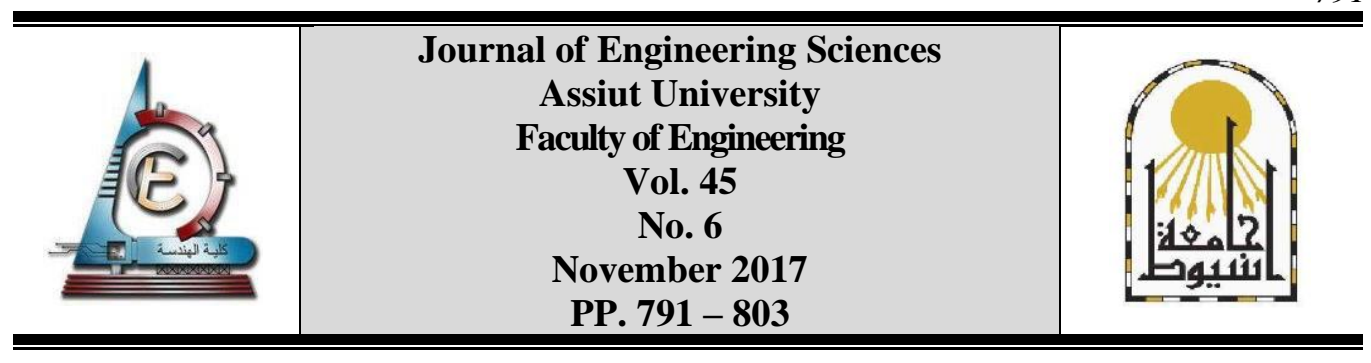

\title{
RECYCLED SHIPPING CONTAINERS AS A TOOL TO PRACTICE MODULARITY IN ARCHITECTURE STUDIO
}

\author{
Ebtehal Galal El-Deen Mohamed
}

\author{
Department of Architecture. Faculty of Engineering, Mataria. Helwan University, Egypt
}

Received 5 September 2017; Accepted 17 October 2017

\begin{abstract}
The paper proposes a new approach to practice modularity in architecture studios by offering fixed shipping container units to be adopted in architecture educational process, the main goal of this educational adaptation is to offer a new alternative to assess the Modular Design Process by integrating sustainable approach with educational one for early years' students, Qualitative and quantitative research designs were adapted to provide flexible approaches through the course stages which depends on the aim of each stage. Different methods will be applied to students to examine the effectiveness of using containers to develop modularization concept through all design process, and to encourage them discussing new skills with developing old ones. The grading system, analyzing data, two questionnaire and external judgment committee will be the main tools to be used. Recommendations will offer other methods to improve teaching Modularity, especially in the preliminary stages of design process to develop and enhance the student's skills.
\end{abstract}

Keywords: Shipping containers, Cargo containers, Cargotec Ture, architectural education, Modular design. Design Studio.

\section{Introduction}

Architecture studio plays a major role in forming student's architectural identity through different educational steps. Dealing with limits is one of a classic problem in the design studio, limitation in time, area, budget and topography, etc. Dimensions is a major limitation concern which is part of students understanding the nature of structure's loading limits, furniture and finishing material standard as well, which led to a modular design concept.

Modularity is the use of the same module in many configurations, resulting in large variety of design alternatives, with bringing several advantages includes: reducing construction time, cost, maintenance and replacing elements. It is upgradable, serviceable, and flexible. As a result, modular design pushes out the productivity in design creation [1]. Several attempts have been made to develop the way of teaching students the techniques of using modularity in design, the most popular is using Grids, However, a major problem with this kind of technology that it is dull, lacking interest or excitement, especially with the software revolution and the acceleration of time. As a result, most of the students ignore this part and start designing directly by using empty CAD file without any rules. On the other hand, the modern cargo container architecture is derived from the concept of 
using containers in architecture that has been developed over the past 300 years. Such units have durability and could have a long lifespan up to 20 years if not exposed to harsh, unpleasant conditions. Containers sometimes stay nearly $56 \%$ of its lifespan, either idle or be repositioned while being empty. It is extremely expensive to ship empty containers back to their origin. Thus, reusing them again could lower the carbon footprint and the total embodied energy in construction [2].

In a previous study conducted about using recycled materials in architecture, it was concluded that the lack of knowledge and understanding of such materials was a major barrier in dealing with them in design. It was found out that most of architects did not know about its aesthetic and design possibilities. The research recommended that sharing the practical knowledge will decrease the barriers that still exist [3]. Another article focused on the basic knowledge about shipping containers were supported by eight existing examples varied from a small size shipping container cabin which constructed in 2008, to a complete city "London Container City 2002" which was a simple work place built with only reused containers. The paper showed that using containers is not a rigid design solution for spaces according to its modularity and infinite variation of space configuration and form creation [4]. An educational adaptation offered using containers with architecture students by using Problem-based learning (PBL) methodology, the study concentrated on the implementation of cargo containers as a structural unit for a small project such houses or office spaces design. Due to time limitation, it was not a design studio activity, but the course focused on handing-out pre-defined building types instead of developing flexible new ones [5]. Another research studied the availability of using those units in hot humid regions has showed that major modifications were needed to ensure comfortable internal environment for a tropical climate, which was a significant constraint of using such models beside the cost of exporting the units from its origin. The research concluded that potential limits in the tropics could be outweighed by advantages, especially for those who are in need for habitable space [6].

\subsection{The aim}

The paper aims at focusing on the experience of teaching and practicing the concept of Modularity to early years' Interior Design Students. In addition to understanding its importance on vertical, horizontal dimensions, and its effect on the design process and decisions, by offering shipping container units with some removable boundaries but fixed structure to form different spaces for a selected project.

\subsection{Research problem}

As shown previously, many researches in the field of Architecture focused on one attempt in the educational process, either modular design or using recycled materials such as shipping containers, as a sustainable design approach. However, no previous study has investigated the possibility of merging both approaches to create a new methodology for practicing modularity in design studios.

Therefore, this study structure illustrated in Fig. (1) set out to assess the effect of using both techniques to develop teaching process in the design studio, by addressing the following questions:

- Will using a shipping container as a teaching method for delivering the concept of modularization to a novice student will be effective or not. 
- Another question is whether flexibility in accepting designs by many techniques will lead to a better result with modularity than asking for a mandatory request from all (regardless individual skills!).

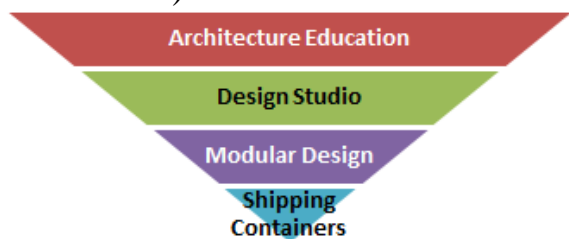

Fig. 1. The work structure [7].

Data for this study were collected throw three months of working with the student to submit a final project. A mixed approach was adopted here and the findings should make a significant contribution to the field of architectural education. The readers should keep in mind that the study is based on "one project type" and the same method could be applicable for other kinds of projects.

\subsection{Hypotheses}

- The work will measure the effectiveness of using multi technical procedures to deliver the idea of modularization,

- Developing design methods through the different process by mandatory requirements will force students to learn a new skill.

\subsection{The Methodology}

The methodological approach taken in this study is a mixed methodology based on qualitative and quantitative research strategies which make it flexible to the adjustment in the process during the semester. The process was conducted through Inductive logic research to find out how the student will deal with the modular design by using fixed dimensional recycled units in their project. It was an interactive process not a linear one which changed per the situation and stage's need.

\section{Materials and methods}

The study took place in Kuwait City, in a new private institution that provides some architectural courses for interior design department. It was done to the students of class 2016-2017 in Interior Architectural department (there were 12 students in this class), as the $2^{\text {nd }}$ course of Architecture Design studio, besides other interior and architectural courses to fulfill the requirements of the Architectural Interior Bachelor degree.

It is worth mentioning that there is only one governmental university in Kuwait with one Architecture Collage. They accept only 40 to 50 students in a class per year. The Private Institution in which the study takes place is the only one that awards an Interior Architecture Bachelor, with 10 to 20 students in a class per year.

At the beginning of the course, a questionnaire was formed to collect information from students to weight their knowledge about working with fixed elements in an architectural or interior design studio in previous courses. Theoretical lectures were delivered to draw out the idea of Modularization and Sustainability. Then, there was a group research aiming at encouraging students to find main information about containers such as plan creations, form generation, building cost, labor time, substitution, replacement, fixation, 
maintenance, arrangements, number of floors and the structure system. The students were also asked to analyze similar projects to collect users' feedback.

Those items will be analyzed to measure the student benefits. Other items were covered without analytics like materials, covering and cladding, designing in hot climate, pricing, users feedback in similar projects, advantages and disadvantages, they also had to analyze and criticize three similar projects in advanced as shown in Fig. (2).

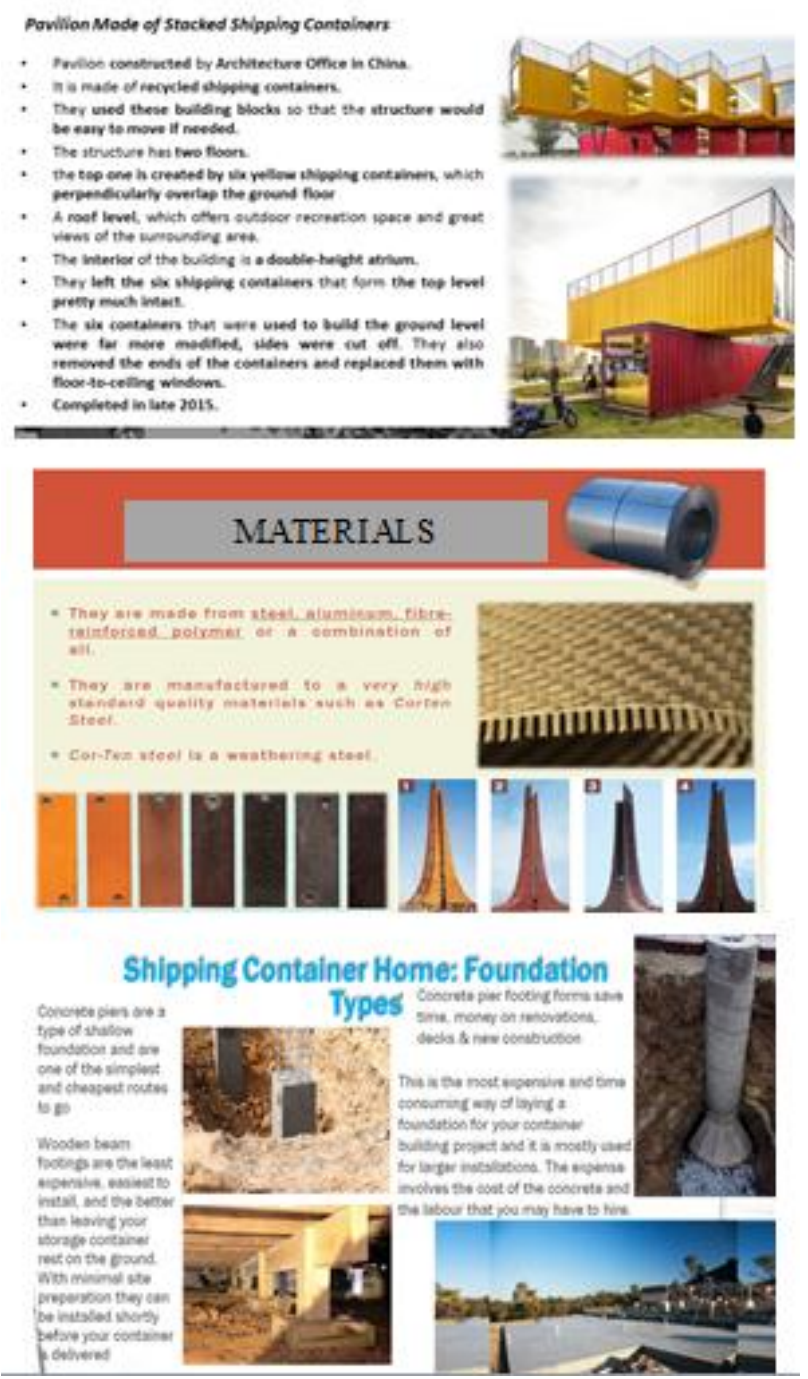

Fig. 2. Different slides from group researches which covered various topics about shipping containers [8].

This stage was followed by general discussion and brain storming about the Possibilities and Obstacles of designing with such unit. After discussion, they were asked to start thinking about using this unit to design an Entertaining Project on the Arabian Gulf Shore which is the most favorite projects here in Kuwait's shore, and it was only one project type for all students. The site framed on the map Fig. (3). 


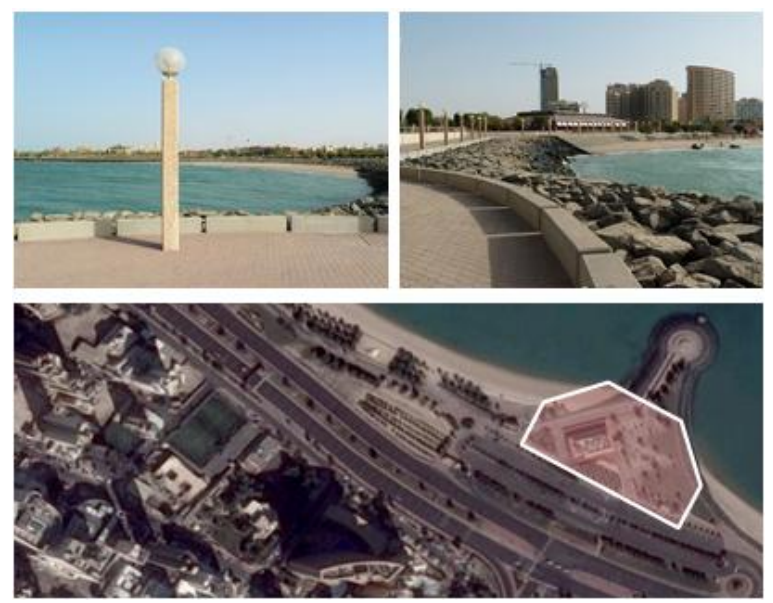

Fig. 3. Location of the project's [9].

And the program consists of:

- Six Restaurants: Two restaurants designed with three modular containers,

Two restaurants designed with two modular containers,

Two restaurants designed with one modular container,

- Six Cafés: $\quad$ Two Cafés designed with three modular containers,

Two Cafés designed with two modular containers,

Two Cafés designed with one modular container,

- Service area (toilets, pray area, waiting area)

- Retail stores, outdoor sitting, and activity area,

- Optional space (kids playing indoor area, Spa, or Gymnasium).

When they started, they guided to use manual grids and sketches as a first step to develop freehand skills instead of using CAD, followed by using standard sticky color notes presented in Fig. (4) with scale 1:300 which gave approximate dimensions as of a standard 40' shipping container $12 * 2.5 * 2.6 \mathrm{~m}$ which was our most important modular design unit as Fig. (5) shown.

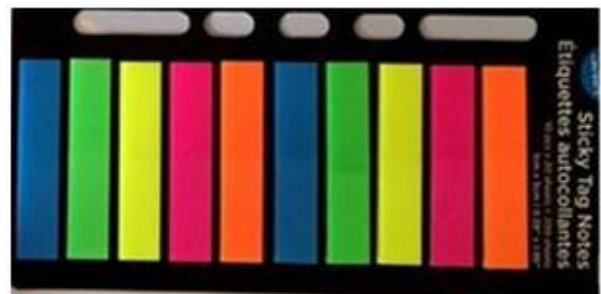

Fig. 4. Sticky notes $10 * 40 \mathrm{~mm}$ which used to simulate standard 40 ' containers, and the ordinary manual grid [10].

Each stage of work was marked and analyzed to guide the students in the next step. The course extended through 12 weeks of work and observation. At final submission, student where asked to complete a $2^{\text {nd }}$ questionnaire to weight goals that have been achieved, which delivered along with $3 \mathrm{~d}$ physical model and final poster. 


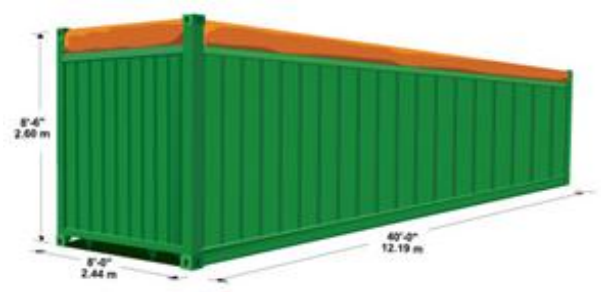

Fig. 5. The standard 40' Container [11].

\section{Results}

At the begging with interior architectural students of class 2016-2017, we found most of them did not get enough information before about modular design concepts, the percentage was $60 \%$ as illustrated in Fig. (6), they just worked on two architectural projects in previous years without focusing on the importance of using modules.

The background lacked to the most relevant information about it, and they didn't know where to start. So, going through many theoretical lectures was the start point for the design.

After that, to examine the hypotheses, different ways were tested to blend the modularity of recycled shipping containers and the new international trend in building with them, which grown over the past several years due to their advantages and they called Cargotecture

"The term Cargotecture was coined in 2003 to describe a building built partially or entirely from recycled ISO shipping containers [12].
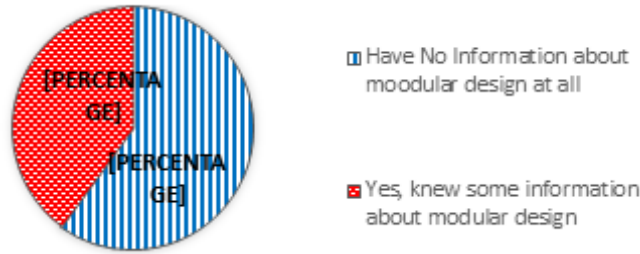

Fig. 6. The percentage of the student that didn't know or work with modular design before [7].

Benefits of using such a standard unit were proved to the student through there group research, the efforts done by groups were incredible and filled with valuable information that impressed them, especially because it was new for $30 \%$ of them to know that containers could be a useful element in the architecture according to the first questionnaire. During interactive working process, we noticed that some students still face a problem in imagining the way to combine the units using grids and sticky notes, those were lead to use $2 \mathrm{~d} C A D$ and $3 \mathrm{~d}$ physical models to develop their idea and the result was shown in Fig. (7) for techniques. 

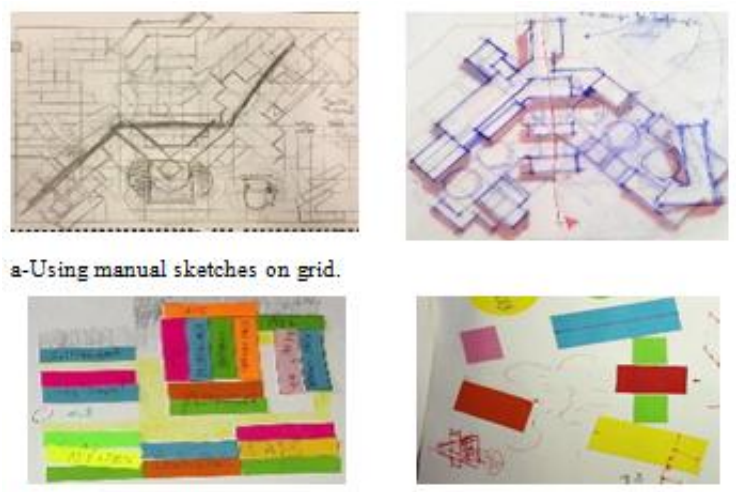

b-Using colored sticky notes paper
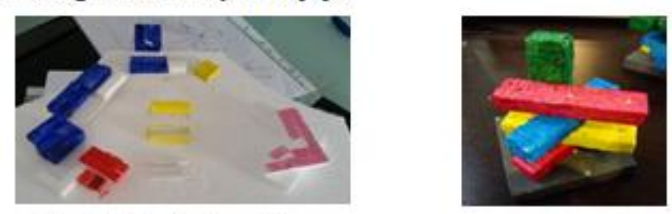

c- Using $3 \mathrm{D}$ phyiscal models.
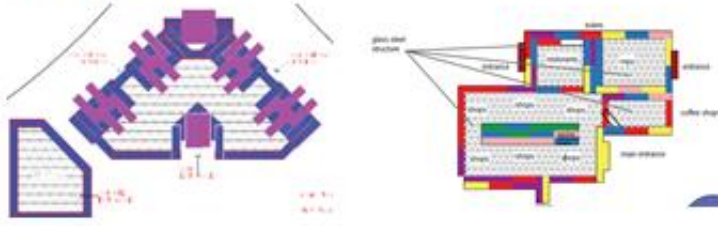

Fig. 7. A,B,C,D All techniques that used during design [8].

It is important to mention that not all students worked equally with each technique, some used one method more than others, and others tried many methods to test new skills as shown in Fig. (8), many students fail to create a passion for that new area, and the result was not creative as shown Fig. (9), which appears in different stages. Few of them worked out to develop those gained skills in $3 \mathrm{~d}$ modeling till the final submission which will appear later.

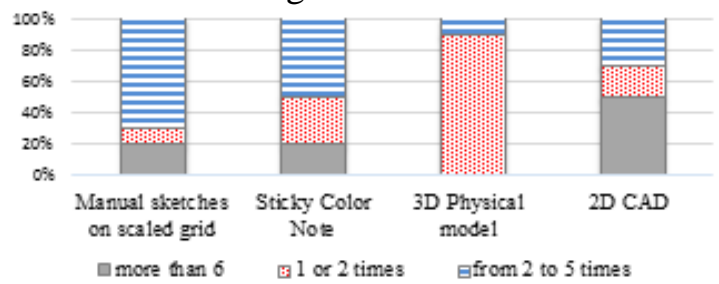

Fig. 8. The percentage of a number of times students used each technique [7].

The grading system varies per the developed stage to measure different items such as creativity, developing process, and the completion of each stage. At the end of working weeks' final grade was taken to evaluate the final submitted project, parallel with the $2^{\text {nd }}$ Questionnaire to get student's feedback about many points such as:

A. Favored techniques:

Working with new technologies like sticky notes and grids was challenging, but they prefer CAD again as presented in Fig. (10). 


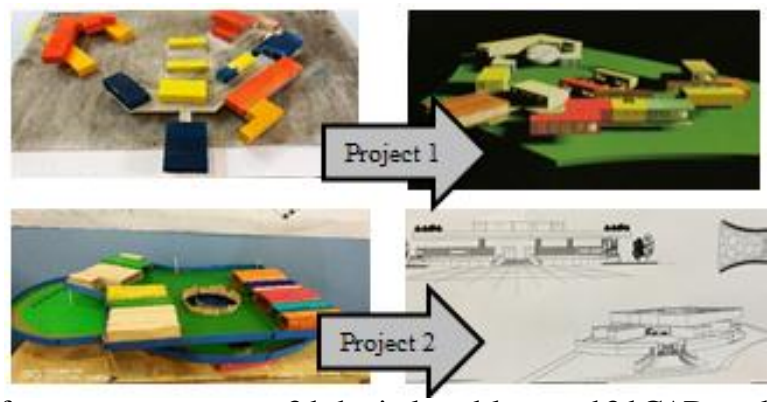

Fig. 9. Modest result for some attempts to use 3d physical model vs good 3d CAD results for the same project [8].

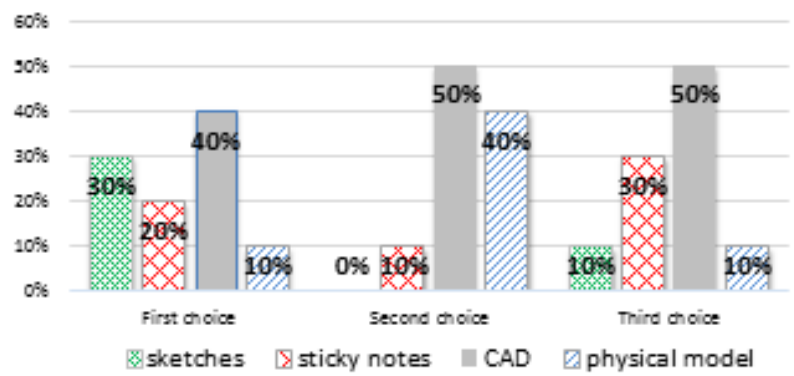

Fig. 10. The students favorit techniques to work with in the nect project [7].

\section{B. Main constraints:}

Dealing with dimension limitation was the greatest problem for almost half of the class, because it was the first time to be restricted in a limited aspect which covers heights, widths, and lengths, followed by periods ( 12 weeks is the average term length and it was only one project for the entire course). What was encouraging is that only $7.7 \%$ of the students found Modularity as a design problem, which means that more than $90 \%$ of them worked with it easily as shown in (11).

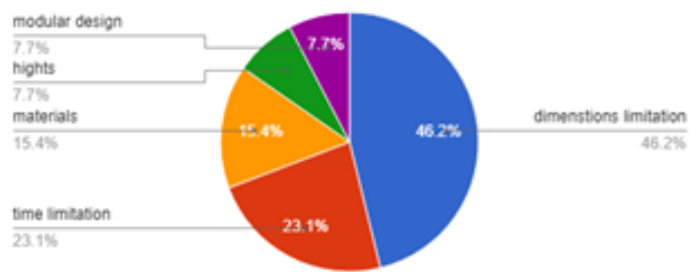

Fig. 11. The constrains that met the students during the course [7].

\section{Using Cargotecture in other projects:}

In our tested sample $40 \%$ of the students pointed to the possibility of using Cargotecture in their graduation project vis-a-vis $50 \%$ who might use it, because they found it unique and promising, and it would be suitable for many types of projects, especially that they obtained enough information that could help them to concentrate on design ideas and concepts.

One of the big advantages of this approach which appeared in the final submission was that students could test each technique (grids, sticky notes, 2,3d CAD, physical model) freely to find out new skills and work to develop it in such a short time. The previous section has shown that different attempts were made to improve working with fixed modules, but this approach may fail if growing technique was set to one method only due to the differences in student's skills in a department which architecture studio courses is not major. 
Ebtehal Galal El-Deen Mohamed, Recycled shipping containers as a tool to practice modularity .....

The only disadvantage of such a method was using many techniques in a short time which was confusing for some of them who tried to examine each one. To verify this method, the external committee was invited to evaluate final projects and to assess the extent of modularization in all architectural elements. As shown in Figs. (12-15) selected from some students' projects, the presence of modularization was ultimately appearing in layouts, plans, elevations and physical models as well, which affects the final grades.

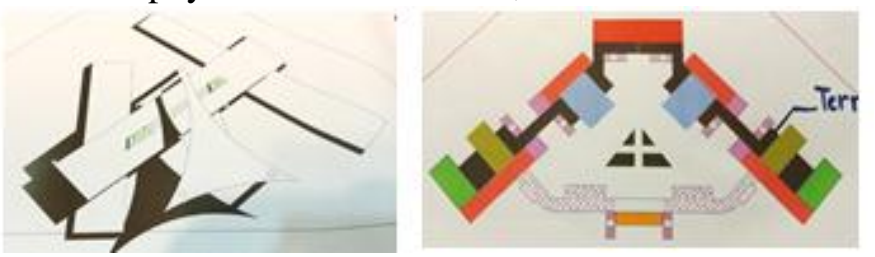

Fig .12. Examples of Modularization in layout concept [8].

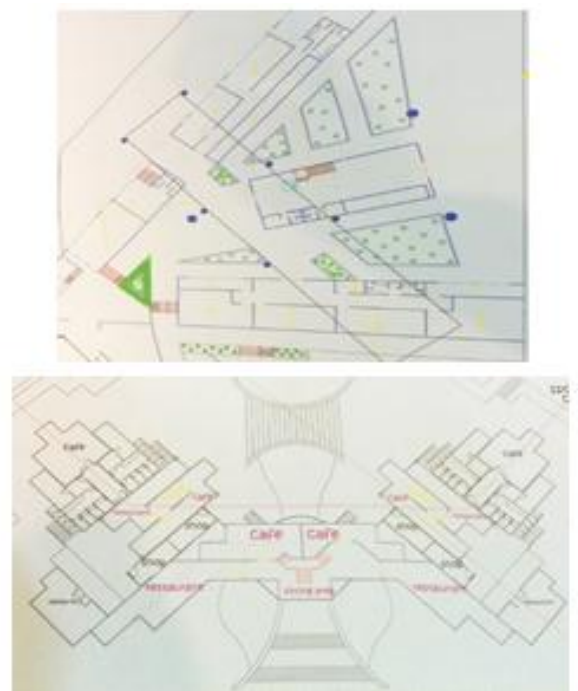

Fig .13. Examples of Modularization in plan design [8].

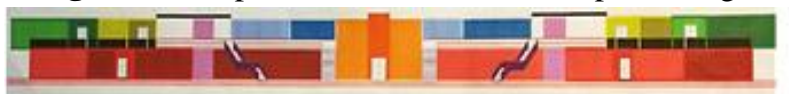

Fig. 14. Examples of Modularization in elevations [8].
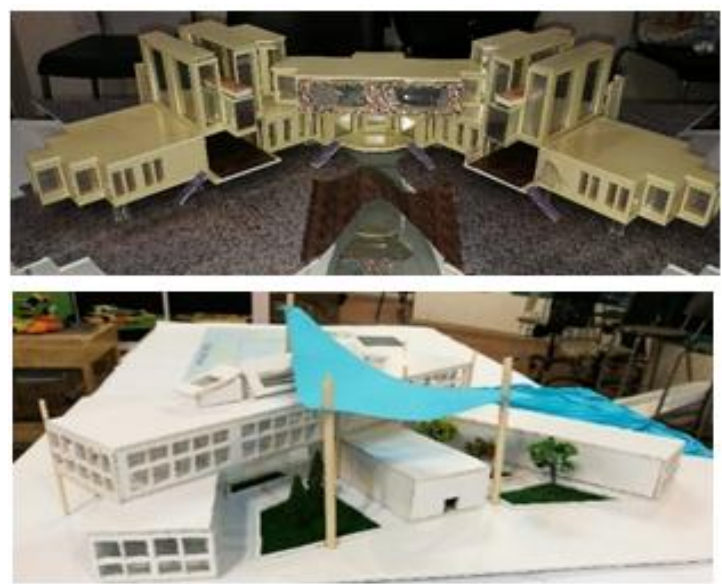

Fig. 15. Examples of Modularization in 3D model [8]. 


\section{Discussion}

We examined the possibility of using multi technical procedures in this paper to deliver the idea of modularization to a nearly novice architect students, by adapting recycled shipping containers with flexible developing solutions to improve the design. It was the primary purpose of the paper to draw attention to improve teaching design basics like using modules in design by using Cargotecture which was innovative. Our observations is that teaching is an interactive process between the teacher and the architect students are not new, but using this flexible technique to teach them about modularization and recycling at the same time was novel and efficient to deliver the idea of using standards and fixed dimensions. The main limitation result is time and lacked teaching assistant to enrich the experience.

In the end, the questionnaire proved, through evaluation of the final benefits, that most of the students "more than $80 \%$ " started designing with good information about containers' standards and advantages through the research process which makes it easier for them to examine, visualize the units, and know its limitations as shown in Fig. (16).

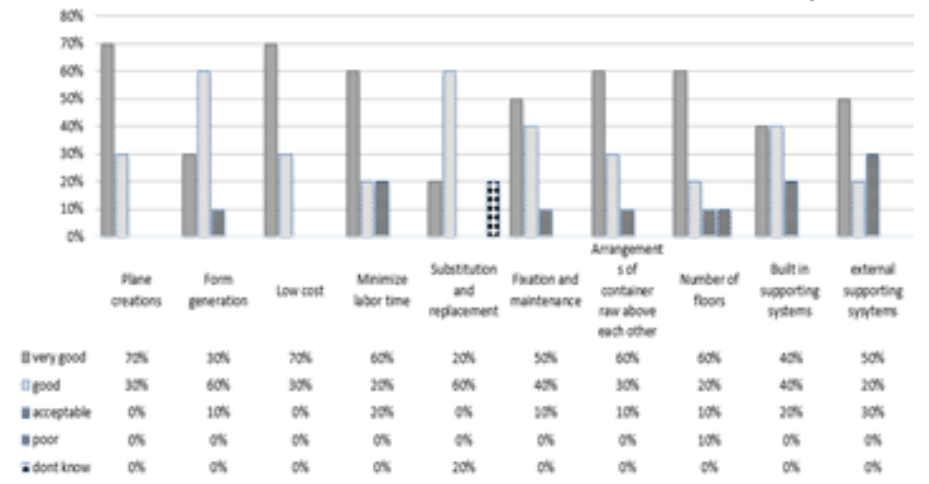

Fig. 16. The quality of informationt that they gained from the group research [7].

Students understood the central concepts of using modules in design (2D, 3D) which illustrated in Fig. (17), and that because they passed through successive stages to develop their idea by using different techniques which matched individual skills. Testing those methods allowed students to focus on improving their design to employ the benefits derived from using fixed dimensional containers; they got the aesthetics and sustainability of modular design units in architecture in general.

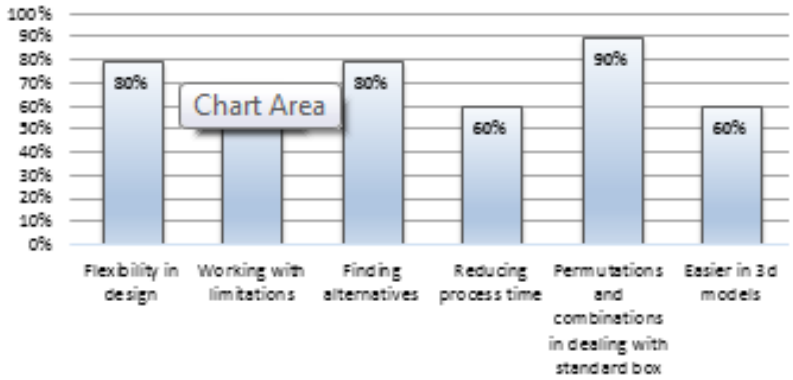

Fig. 17. The students feedback about what they learned from using modularization in design [7].

Judgment committee at the final stage, agreed with how much the group benefited from the experience in delivering the concept of modularization which appears clearly in the final project submission. As shown in Fig. (18), almost 2/3 of students got the idea of modularization and that is displayed in the concept and design of most projects. $22.22 \%$ 
got between $90: 100 \%$ of the final grade, 37.04\% of the students got between 70:89\%, $33.33 \%$ of them earned from $50: 60 \%$, and about $7.41 \%$ failed to submit the projects for different reasons such regular absence or not presenting the final project.

The most likely explanation of the negative result of bad performance from some students who worked with many techniques that they didn't get enough time to improve any.

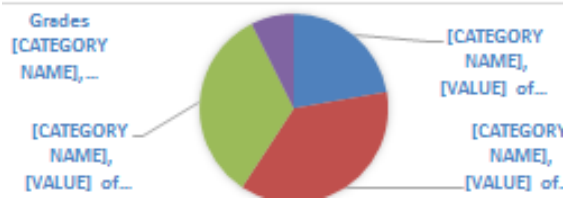

Fig. 18. The grades percentage according to the final jury "presence of modularity in the project components" [7].

\section{Conclusion}

The main goal of this educational adaptation is to offer a new alternative to assess the modular design process by integrating sustainable approach with educational one for early years' students. One of the more significant findings to emerge from this study is that using innovate ideas to develop architectural educational process will lead to innovative results as well. It was also shown that flexibility in handling students individual skills helped them to do their best and spend all time needed to design project according to what they work best with.

Finally, several important limitations need to be considered. First, using modular containers could be suitable for limited projects which need limited spaces dimensions according to its structural features which eliminate the height and removing side walls. Second, the location of the determined project needs to be chosen carefully to extend the useful life of the project to insure indoor comfort environment and to facilitate the unit's transportation. Student survey shows positive feedbacks, but improvement is necessary to increase the effectiveness of this activity by applying it to larger groups with different project functions and different standard units. To do that a future study investigating using LEGO "a plastic construction toys consists of modular colorful interlocking plastic blocks", Matches or Tunnel Form standard units would be very interesting in delivering the idea of modularization in design for students to assess the idea that modular construction simplifies the design process without harming the aesthetics or the function of the project.

\section{Recommendations}

Using modular units like shipping containers was a suggested design tool, along with using sketches, sticky notes, and simple physical models to deliver the idea of Modularization. However, doing this in only one term will not be enough alone, as more efforts need to be exerted to improve teaching Modularity, especially in the preliminary stages of design process to improve the students' skills by offering more alternatives to develop and enhance these talents, such as lectures, sketches, quizzes and exercises on the drawing board for many classes, to teach them the importance of using modules in design, and the sense of dimensions in a vertical, horizontal and diagonal modules.

\section{REFERENCES}

[1] McCluskey, A., "Modularity: upgrading to the next generation design", http://www.connected.org/media/modular.html, (Accessed 14-1-2017).

[2] "Transport Geography on the Web," Hofstra University, New York, USA, https://people.hofstra.edu/geotrans/eng/ch3en/conc3en/containerlifespan.html, (Accessed 19-2-2017). 
[3] Munn, S., Soebarto,V., "The issues of using recycled materials in architecture", The 38th International Conference of Architectural Science Association ANZAScA, Launceston, Tasmania, 2004.

[4] Radwan, A., "Containers Architecture, Reusing Shipping Containers in making creative Architectural Spaces", International Journal of Scientific \& Engineering Research, Vol. 6, No. 11, pp. 1562-1577, 2015.

[5] Christopher, M., Semih, G., Stuart, W., "Educational Adaptation of Cargo Container Design Features", American Society for Engineering Education ASEE Zone III confercance, 2015.

[6] Ismail, M., Al-Obaidi, K., "Container Architecture in the Hot-Humid Tropics: Potential and Constraints", 4th International Conference on Environmental Research and Technology (ICERT 2015), Malaysia, 2015.

[7] Auther, 2017.

[8] Arch Studio Course, photographed by Ather, 2017.

[9] "Google https://www.google.com.kw/maps/@29.3700043,48.0128752,677m/data=!3m1!1e3?hl=en, (Accessed 2-5-2017).

[10] "Pinterest", https://www.pinterest.com/explore/sticky-notes/?lp=true, (Accessed 2-5-2017).

[11] "Ports Shipping Logistics", http://portsandshipping.blogspot.com/2012/06/types-and-sizesof-cargo-shipping.html, (Accessed 9-2-2017).

[12]"Cargotecture", http://www.cargotecture.com/, (Accessed 8-2-2017).

[13]Pagnotta, B., "The Pros and Cons of Cargo Container Architecture," ArchDaily , http://www.archdaily.com/160892/the-pros-and-cons-of-cargo-container-architecture, (Accessed 18-2-2017).

[14]Nady, R., "When Beauty and Efficiency Meet: Modular Architecture", Arch2O, http://www.arch2o.com/language-modular-architecture/, (Accessed 18-2-2017).

[15] Smith, R. E., "Prefab Architecture a Guide to Modular Design and Construction", John Wiley \& Sons Inc. New Jersey, p. 259, 2010. 
Ebtehal Galal El-Deen Mohamed, Recycled shipping containers as a tool to practice modularity .....

حاويات الثحن المعاد تدويرها، كأداة تصميمة لممارسة النمطية في استوديو التصميم المعماري الملفص العربى

تقترح الورقة البحثية نهجا جديدا لاستخدام الوحدات النمطية "الموديول التصميمي" في استوديوهات العمارة من خلال تقديم وحدات حاويات الثحن ذات الابعاد الثابتة و التي سيتم تكييفها في التعملية التعليمية

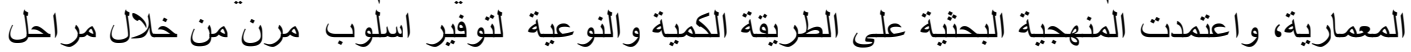
البحث المختلفة والتي تعتمد على الهدف من كل مرحلة. وسيتم تطبيق تقنيات مختلفة مع الطلاب لداب لدراسة

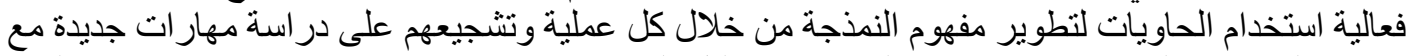

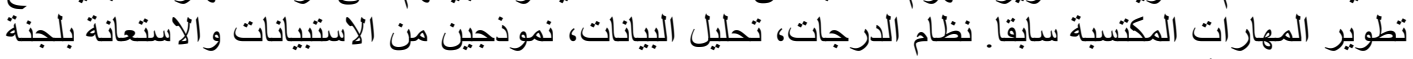

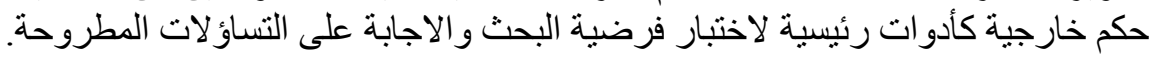

